\title{
Uji Efektivitas Beberapa Minyak Atsiri terhadap Pertumbuhan Microsporum canis secara in Vitro
}

\author{
Bunga Saridewi Nurmansyah ${ }^{1}$, Aziz Djamal $^{2}$, Asterina $^{3}$
}

\begin{abstract}
Abstrak
Dermatofitosis merupakan masalah kesehatan masyarakat yang penting di daerah tropis. Minyak atsiri merupakan salah satu potensi alam Indonesia yang diketahui memiliki daya antifungi. Tujuan penelitian ini adalah mengetahui efektivitas beberapa minyak atsiri (serai wangi, kayu manis dan cengkeh) sebagai antijamur dalam mengendalikan pertumbuhan Microsporum canis penyebab dermatofitosis secara in vitro. Penelitian dilakukan di Laboratorium Fitopatologi KP Balittro Laing Solok dari Februari sampai April 2014. Studi eksperimental ini dilakukan dengan metode pengenceran disusun dalam Desain Rancang Acak Lengkap dalam Faktorial. Faktor pertama adalah jenis minyak atsiri (daun serai wangi, daun kayu manis, daun cengkeh). Faktor kedua adalah tingkat konsentrasi minyak atsiri (100 ppm, 250 ppm, 500 ppm, 1000 ppm dan 2000 ppm). Hasil penelitian ini menunjukkan bahwa minyak atsiri daun serai wangi, daun kayu manis dan daun sarasah cengkeh efektif dalam menekan pertumbuhan $M$. canis secara in vitro. Ketiga minyak atsiri pada konsentrasi $500 \mathrm{ppm}$ telah mampu menghambat pertumbuhan $M$. canis hingga 100\%. Minyak atsiri daun sarasah cengkeh memiliki efek antifungi paling tinggi $(89,17 \%)$, diikuti minyak atsiri daun serai wangi $(80,98 \%)$ dan kayu manis $(77,07 \%)$.
\end{abstract}

Kata kunci: minyak atsiri, serai wangi, cengkeh, kayumanis, microsporum canis

\section{Abstract}

Dermatophytosis is an important public health problem in tropical areas. Essential oil is one of natural potential from Indonesia has been predicted as antifungal. The objective of this study was to detect effectivity some essential oils such as citronella, cinnamon and clove as antifungal to control the growth of dermatophyte infections caused by Microsporum canis by in vitro. The study was done in the Laboratory of Phytopathology KP Balitro of Laing Solok from February until April 2014. This is an experimental study with dilution method arranged in Complete Randomized Design in factorial. The first factor was the kind of essential oil (citronella leaf, cinnamon leaf and clove leaf). The second factor was the level of concentration of the essential oil (100 ppm, 250 ppm, 500 ppm, 1000 ppm dan 2000 ppm). The result of this study showed the essential oil of citronella, cinnamon and cloves effective in suppressing the growth of M. canis. The three essential oil at a concentration of $500 \mathrm{ppm}$ was able to inhibit the growth of $\mathrm{M}$. canis to 100\%. Clove essential oils have the highest antifungal effect (89,17\%), while citronella essential oil $80,98 \%$ and cinnamon $77,07 \%$.

Keywords: essential oil, citronella, cinnamon, clove, microsporum canis

Affiliasi penulis: 1. Pendidikan Dokter FK UNAND (Fakultas Kedokteran Universitas Andalas Padang), 2. Bagian Mikrobiologi FK UNAND, 3. Bagian Kimia FK UNAND.

Korespondensi: Bunga Saridewi NurmansyahEmail:

bunga_saridewi@yahoo.com Telp: 085263040728

\section{PENDAHULUAN}

Microsporum canis merupakan salah satu jenis jamur golongan dermatofita penyebab dermatofitosis. Ada $32 \%$ dari kasus dermatofitosis disebabkan oleh 
M.canis dengan manifestasi klinis berupa tinea kapitis dan tinea korporis. ${ }^{1}$ M. canis menjadi penyebab utama tinea kapitis $(92,8 \%)$ dan tinea korporis $(65,4 \%)$ dari pada golongan jamur dermatofit lain. ${ }^{2}$

M. canis memiliki patogenitas yang lebih kuat dan infeksi yang lebih bergejala dibanding dermatofit lain, ini disebabkan oleh produksi enzim protease Sub3 dan Mep3. Agar bertahan dari imunitas hospes, M. canis memiliki kompleks dinding sel berupa mannan yang menekan kerja cell mediated immunity, sehingga eliminasi jamur oleh hospes dapat dihalangi. ${ }^{3}$

Indonesia sebagai daerah tropis dengan temperatur yang hangat serta kelembaban yang tinggi memudahkan pertumbuhan jamur termasuk golongan Dermatofita. ${ }^{4}$ Populasi dengan status ekonomi rendah, sanitasi yang buruk, lingkungan yang sesak, kontak dengan binatang, penggunaan antibiotik, kortikosteroid serta antineoplastik juga meningkatkan risiko infeksi oleh dermatofit. ${ }^{5}$ Hiperhidrosis, obesitas, diabetes melitus, dan gangguan imunitas juga berperan sebagai faktor predisposisi yang berasal dari tubuh hospes. ${ }^{6}$

Dermatofitosis tersebar diseluruh dunia dengan prevalensi mikosis superfisisal mencapai $20-25 \%$ dari seluruh populasi. $^{7}$ Di Indonesia, insidensi dermatomikosis terhadap seluruh kasus dermatosis di berbagai rumah sakit pendidikan dokter pada tahun 1998 menunjukkan angka yang bervariasi. ${ }^{8}$ Di rumah sakit Dr. M. Djamil Padang, pada tahun 2011 angka dermatofitosis mencapai $76,6 \%$ dari seluruh kasus dermatomikosis. ${ }^{9}$

Pada dekade ini, penelitian mengenai bahan alami terus meningkat, hal ini seringkali dihubungkan dengan keterbatasan obat-obatan sintetis dalam hal efek samping, toksisitas tinggi, tingkat rekurensi, interaksi. $^{10}$ Bahan alami seperti minyak atsiri serai wangi, kayu manis dan cengkeh telah secara luas digunakan sebagai pengobatan tradisional, penyedap makanan dan minuman serta wangi-wangian. Penelitian untuk membuktikan efektivitas minyak dari tumbuhan atsiri sebagai antibakteri dan antijamur juga telah dilakukan. Meskipun begitu, informasi mengenai aktivitas antifungi minyak atsiri cengkeh, kayu manis dan serai wangi terhadap Dermatofit masih terbatas.
Penelitian ini dilakukan dengan tujuan mengetahui efektivitas antifungi minyak atsiri serai wangi (Cymbopogon nardus), minyak atsiri kayu manis (Cinamomum burmanil) dan minyak atsiri cengkeh (Eugenia aromatica) terhadap M. Canis penyebab dermatofitosis.

\section{METODE}

Penelitian dilaksanakan di Laboratorium Pascapanen dan Fitopatologi Kebun Percobaan Balai Penelitian Tanaman Rempah dan Obat Laing Solok pada Februari sampai April 2014.Penelitian bersifat eksperimental, disusun dengan menggunakan desain Rancang Acak Lengkap (RAL) dalam Faktorial dengan 15 perlakuan, 3 kali ulangan. Sebagai faktor pertama adalah jenis minyak atsiri (SW. minyak atsiri daun serai wangi); KM. minyak atsiri daun kayu manis; CK. minyak atsiri daun cengkeh)dan tingkat konsentrasi minyak atsiri (C1. 100 ppm; C2. 250 ppm; C3. 500 ppm; C4. 1000 ppm; C5. 2000 ppm) sebagai faktor kedua.

Koleksi Minyak Atsiri: Minyak atsiri diperoleh dengan cara destilasi uap terhadap daun serai wangi, daun kayu manis dan daun sarasah cengkeh di Kebun Percobaan Laing. Alat suling yang digunakan prototype Balai Penelitian Tanaman Rempah dan Obat Bogor dengan sistem kukus menggunakan ketel ukuran $3 \mathrm{~kg}$. Penyulingan dilakukan selama 2 jam. Minyak atsiri yang diperoleh masing-masing disimpan dalam botol berwarna gelap dan tertutup kemudian disimpan ditempat yang tidak terkena cahaya. Masingmasing minyak selanjutnya ditambahkan pengemulsi dan pelarut hingga didapat formulasi $25 \%$ agar masing-masing minyak teremulsi sempurna.

Isolat Microsporum canis: Isolat diperoleh dari Laboratorium Mikrobiologi Fakultas Kedokteran Universitas Indonesia. Isolat diperbanyak dengan menggunakan media tumbuh Sabouraud Dextrose $\operatorname{Agar}(\mathrm{SDA})$

Uji efektivitas minyak atsiri: Pengujian dilakukan dengan metode pengenceran. Masing-masing formulasi minyak atsiri $25 \%$ dicampurkan sampai 
homogen ke medium SDA steril sesuai konsentrasi yang diuji (100 ppm, 250 ppm, 500 ppm, 1000 ppm dan 2000 ppm) dan kontrol (0 ppm) pada suhu $45^{\circ} \mathrm{C}$ sesuai dengan rumus $\mathrm{V}_{1} \mathrm{~N}_{1}=\mathrm{V}_{2} \mathrm{~N}_{2}$. Medium selanjutnya dituangkan ke cawan petri dan biarkan sampai membeku pada suhu kamar. Setelah membeku, dilakukan inokulasi jamur Microsporum canis, fungal mat dipotong dengan cork borer steril ukuran diameter $6 \mathrm{~mm}$ dari biakan murni yang berumur 8-10 hari. Fungal mat diletakkan ditengah medium yang telah diperlakukan, lalu diinkubasikan dalam inkubator pada suhu $28^{\circ} \mathrm{C}$. Pengamatan dilakukan dengan mengukur diameter koloni $M$. canis selama 12 hari.

Penilaian efektivitas minyak atsiri: Penilaian efektivitas minyak atsiri dapat dilihat dari persentase penekanan pertumbuhan koloni Microsporum canis dengan menggunakan rumus. ${ }^{11}$

$$
P=\underline{K-T} \times 100 \%
$$

\section{$\mathrm{P}=$ Penekanan pertumbuhan koloni \\ $\mathrm{K}=$ Diameter koloni pada kontrol \\ $\mathrm{T}=$ Diameter koloni pada perlakuan}

Analisis data: Data yang didapat dicatat, ditabulasi, dan dianalisis secara statistik dengan menggunakan uji ANOVA (Analysis of Variance). Jika didapatkan hasil yang bermakna maka dilakukan uji lanjut dengan DMRT (Duncan's Multiple Range Test) pada derajat kepercayaan $95 \%$.

\section{HASIL}

Hasil penelitian menunjukkan bahwa ketiga minyak atsiri ketiga minyak atsiri yang diuji efektif dalam menekan pertumbuhan $M$. canis. Makin tinggi tingkat konsenterasi efektivitas minyak atsiri daun serai wangi, kayu manis dan cengkeh juga makin meningkat.

Pada akhir pengamatan (HSA12) diameter koloni pada kontrol mencapai 68,33 mm, sementara pada perlakuan minyak atsiri daun serai wangi, daun kayu manis dan daun sarasah cengkeh 100 ppm diameter koloni masing-masing baru mencapai 39,33 mm; 48,33 mm dan 37 mm (Gambar 1).

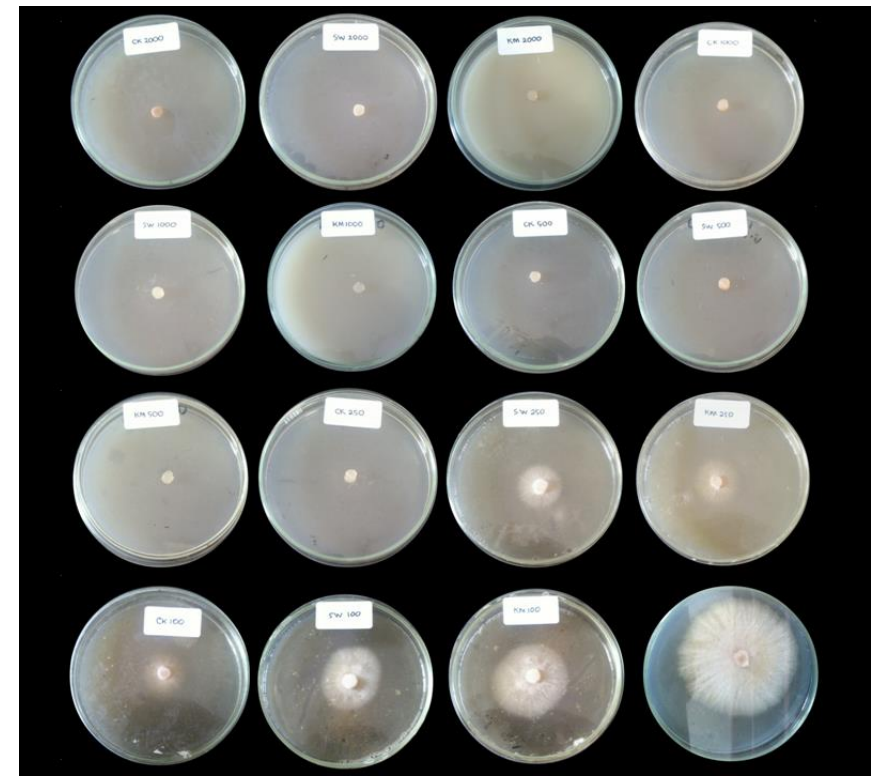

Gambar 1. Diameter koloni Microsporum canis pada berbagai perlakuan minyak atsiri pada akhir pengamatan (HSA12)

Minyak atsiri daun sarasah cengkeh memiliki persentase penekanan tertinggi terhadap pertumbuhan $M$. canis. Berbeda nyata dengan minyak atsiri daun serai wangi dan kayu manis, masingmasing 89,17\%; 80,81\% dan 77,03\% (Tabel 1). Berdasarkan Tabel 1 terlihat bahwa tingkat konsentrasi berbanding lurus dengan penekanan pertumbuhan $M$. canis. Semakin tinggi tingkat konsentrasi, semakin besar penekanan pertumbuhan jamur, tampak $M$. canis tidak mampu tumbuh mulai dari tingkat konsentrasi 500 ppm.

Tabel 1. Pengaruh jenis minyak atsiri dan tingkat konsentasi terhadap penekanan pertumbuhan microsporum canis pada akhir pengamatan (HSA12)

\begin{tabular}{lcc}
\hline \multicolumn{1}{c}{ Perlakuan } & $\begin{array}{c}\text { Penekanan } \\
\text { pertumbuhan (\%) }\end{array}$ & $\begin{array}{c}\text { Rerata } \\
\text { diameter } \\
\text { koloni (mm) }\end{array}$ \\
\hline Jenis minyak atsiri & & \\
Serai wangi & $80,98 \mathrm{~b}$ & 15,66 \\
Kayu manis & $77,07 \mathrm{c}$ & 13,00 \\
Cengkeh & $89,17 \mathrm{a}$ & 7,4 \\
\hline Tingkat konsentrasi & & \\
100 ppm & $40,65 \mathrm{c}$ & 40,55 \\
250 ppm & $71,38 \mathrm{~b}$ & 19,55 \\
500 ppm & $100 \mathrm{a}$ & 0,00 \\
1000 ppm & $100 \mathrm{a}$ & 0,00 \\
2000 ppm & $100 \mathrm{a}$ & 0,00 \\
\hline
\end{tabular}


Angka yang diikuti oleh huruf pada Tabel 1 yang sama pada masing-masing kolom berarti tidak berbeda nyata pada taraf uji DMRT 5\%; (HSA=Hari Setelah Aplikasi).

Pengaruh interaksi jenis minyak atsiri dengan tingkat konsentrasi terhadap penekanan pertumbuhan M. canis pada Tabel 2. Penekanan pertumbuhan pada HSA3 dengan tingkat konsentrasi yang sama oleh minyak atsiri daun serai wangi 250 ppm (57,81\%) berbeda nyata dengan minyak atsiri daun kayu manis $(58,19 \%)$ dan daun sarasah cengkeh $(61,27 \%)$. Pada HSA9 terlihat bahwa minyak atsiri daun sarasah cengkeh 250 ppm berbeda nyata dengan minyak atsiri daun serai wangi dan daun kayu manis 250 ppm, tetapi tidak berbeda nyata pada minyak atsiri daun serai wangi dan daun kayu manis pada tingkat konsentrasi 500 ppm.

Tabel 2. Pengaruh interaksi antara jenis minyak atsiri dengan tingkat konsentrasi terhadap penekanan pertumbuhan Microsporum canis

\begin{tabular}{|c|c|c|c|c|c|c|}
\hline \multicolumn{2}{|c|}{$\begin{array}{c}\text { Perlakuan } \\
\text { (ppm) }\end{array}$} & \multicolumn{5}{|c|}{ Penekanan pertumbuhan (\%) } \\
\hline \multicolumn{2}{|c|}{$\begin{array}{l}\text { Jenis minyak } \\
\text { x konsentrasi }\end{array}$} & \multicolumn{2}{|c|}{ HSA3 } & HSA6 & HSA9 & HSA12 \\
\hline \multirow[t]{5}{*}{ SW } & 100 & 18,37 & $\bar{e}$ & $49,1 \varepsilon d$ & $38,5<\mathrm{e}$ & 42,44 e \\
\hline & 250 & 57,81 & c & $74,7 € \quad b$ & $70,95 \mathrm{~b}$ & $62,44 b$ \\
\hline & 500 & 63,23 & $b$ & $10 \mathrm{c} a$ & $10 \mathrm{C} a$ & $10 \mathrm{C}$ \\
\hline & 1000 & 100 & a & $10 \mathrm{Ca}$ & $10 \mathrm{C} a$ & $10 \mathrm{C}$ \\
\hline & 2000 & 100 & a & $10 \mathrm{Ca}$ & $10 \mathrm{C} a$ & $10 \mathrm{C}$ \\
\hline \multirow[t]{5}{*}{$\mathrm{KM}$} & 100 & 12,13 & $f$ & $26,22 \mathrm{e}$ & $23,65 f$ & $33,66 \mathrm{f}$ \\
\hline & 250 & 58,19 & bc & $61,61 \mathrm{c}$ & $54,05 \quad \mathrm{c}$ & $51,7 \mathrm{C} \quad \mathrm{c}$ \\
\hline & 500 & 63,23 & $b$ & $10 \mathrm{C} a$ & $10 \mathrm{C}$ a & $10 \mathrm{C} a$ \\
\hline & 1000 & 100 & a & $10 \mathrm{C} a$ & $10 \mathrm{C}$ a & $10 \mathrm{C}$ \\
\hline & 2000 & 100 & a & $10 \mathrm{c} a$ & $10 \mathrm{C} a$ & $10 \mathrm{C}$ \\
\hline \multirow[t]{5}{*}{$\mathrm{CK}$} & 100 & 34,80 & $\mathrm{~d}$ & $46,46 d$ & $45,27 d$ & $45,8 \bar{d}$ \\
\hline & 250 & 61,27 & bc & $80,83 b$ & $10 \mathrm{C} a$ & $10 \mathrm{C} a$ \\
\hline & 500 & 63,23 & b & $10 \mathrm{Ca}$ & $10 \mathrm{C} a$ & $10 \mathrm{C}$ \\
\hline & 1000 & 100 & a & $10 \mathrm{C} a$ & $10 \mathrm{C} a$ & $10 c a$ \\
\hline & 2000 & 100 & a & $10 \mathrm{Ca}$ & $10 \mathrm{C} a$ & $10 \mathrm{C}$ \\
\hline
\end{tabular}

Keterangan: (HSA=Hari Setelah Aplikasi); (SW=Serai wangi) (KM=Kayu manis); (CK=Cengkeh).

\section{PEMBAHASAN}

Penekanan pertumbuhan diameter koloni Microsporum canis oleh beberapa jenis minyak atsiri yang diuji menunjukkan potensi minyak atsiri sebagai antifungi. Diameter koloni rata-rata pada perlakuan minyak atsiri daun kayu manis pada HSA12 adalah
15,66 mm (penekanan pertumbuhan 77,07\%), berbeda nyata dengan perlakuan minyak atsiri daun serai wangi dengan diameter koloni rata-rata $13 \mathrm{~mm}$ (penekanan pertumbuhan 80,98\%) serta minyak atsiri daun sarasah cengkeh dengan diameter koloni terkecil 7,4 mm (penekanan pertumbuhan 89,17\%). Sementara diameter koloni pada kontrol telah mencapai $68,33 \mathrm{~mm}$.

Makin tinggi tingkat konsentrasi berbagai jenis minyak atsiri yang diuji, makin tinggi potensi penekanan pertumbuhan. Pada tingkat konsentrasi 500 ppm untuk minyak atsiri daun serai wangi dan daun kayu manis dan 250 ppm untuk minyak atsiri daun sarasah cengkeh, Microsporum canis tidak mampu tumbuh atau dengan kata lain penekanan pertumbuhan mencapai $100 \%$. Interaksi minyak atsiri daun serai wangi, daun kayu manis dan daun sarasah cengkeh dengan tingkat konsentrasi terhadap pertumbuhan diameter koloni jamur uji. Pada konsentrasi 250 ppm, ketiga jenis minyak atsiri sudah menunjukkan penekanan berkisar antara 51,70-100\%, sedangkan pada konsentrasi 500 ppm untuk ketiga jenis minyak tersebut sudah mampu menghambat pertumbuhan koloni M.canis 100\% (Tabel 2).

Berdasarkan data dari kedua tabel tampak bahwa minyak atsiri daun sarasah cengkeh memiliki efek antifungi paling besar jika dibandingkan dengan minyak atsiri daun serai wangi dan daun kayu manis. Perbedaan ini disebabkan oleh berbedanya komponen senyawa kimia pada masing-masing minyak atsiri tersebut.

Minyak atsiri daun sarasah cengkeh memiliki kandungan utama eugenol (71,56\%) dan eugenol asetat (8,99\%). ${ }^{12}$ Eugenol mampu menghancurkan membran mitokondria dan dinding sel sehingga terjadi perubahan struktur sel Dermatofit. ${ }^{13}$ Aktivitas antifungi minyak atsiri cengkeh pun telah diuji oleh Martos et al, bahwa pada konsentrasi $6 \mu \mathrm{L} / 18 \mathrm{~mL}$ (333,333 ppm) minyak atsiri cengkeh efektif terhadap Aspergillus niger dan Aspergillus flavus. ${ }^{14}$ Park et al melaporkan efektivitas minyak atsiri cengkeh pada konsentrasi $0,15 \mathrm{mg} / \mathrm{ml}$ (150 ppm) terhadap Tricophyton mentagrophytes (88\%), T. rubrum (51\%), M. canis (32\%) dan E. floccosum (60\%). ${ }^{13}$ Peneliti lain seperti Chee dan Lee, serta Pinto et al juga membenarkan 
efektivitas antifungi minyak atsiri cengkeh terhadap beberapa jamur. ${ }^{15,16}$

Minyak atsiri daun serai wangi juga menunjukkan efek antifungi yang baik dengan persentase penekanan pertumbuhan $80,98 \%$. Adapun senyawa-senyawa kimia yang terdapat dalam minyak atsiri serai wangi adalah citronellyl acetate, geranyl acetate, $\quad \alpha$-terpineol, $\quad \alpha$-terpinene, limonene, isoeugenol, citronellal, citronellol, linalool, geraniol, citral, nerol, menthone, $\alpha$-pinene, $\beta$-pinene, myrcene. ${ }^{17}$ Senyawa yang mempunyai potensi sangat besar sebagai antifungal adalah sitronellal dan linalool, efektif terhadap jamur Aspergillus candidus, A. flavus, A. versicolor, Eurotium amstelodami, E. chevalieri, Penicillium adametzii, $P$. citrinum, $P$. griseofulvum, dan $P$. islandicum. Minyak serai wangi pada konsentrasi $400 \mathrm{mg} / \mathrm{L}$ (400 ppm) dapat menipiskan dinding sel hifa sehingga menekan $80 \%$ pertumbuhan jamur Aspergillus niger. ${ }^{18}$

Minyak atsiri daun kayu manis memiliki penekanan pertumbuhan sebesar $77,07 \%$, lebih rendah dibanding minyak atsiri daun sarasah cengkeh dan daun serai wangi. Hal ini diperkirakan karena rendahnya jumlah senyawa aktif yang bersifat antifungal oleh minyak atsiri daun kayu manis. Minyak atsiri kayumanis mengandung cinnamaldehyde, cinnamic acid, cinnamyl alcohol, and coumarin. ${ }^{19}$ Cinnamaldehyde merupakan senyawa antifungi utama pada kayu manis. ${ }^{20}$ Mikroskop transmisi elektron mendeteksi perubahan ultastruktural Dermatofit akibat cinnamaldehyde. Perubahan tersebut berupa lisis dinding sel dan membran plasma, disintegrasi mitokondria, membran plasma, dinding sel, nukleus dan isi sitoplasma, distribusi abnormal polisakarida serta kebocoran isi sitoplasma. ${ }^{10}$ Sementara itu, rendemen minyak atsiri dari tanaman kayu manis (Cinnamomum burmani) paling besar didapat dari penyulingan kulit batang (3,45\%), kulit dahan (2,38\%), kulit ranting $(1,95 \%)$ dan yang terkecil dari daun $(1,12 \%),{ }^{21}$ dimana besar kandungan cinnamaldehyde dari kulit batang berkisar antara 69,35\%-74,95\%, dan dalam daun kayu manis hanya $15,46 \% .{ }^{11}$ Hal ini didukung dengan penelitian mengenai uji efektifitas minyak atsiri kayu manis terhadap Fusarium oxysporum, bahwa minyak atsiri dari kulit batang lebih tinggi daya antifunginya dibanding minyak ranting dan daun. Minyak kulit batang pada konsentrasi 500 ppm, minyak ranting dan daun pada konsentrasi 1250 ppm mampu menekan pertumbuhan koloni Fusarium oxysporum $100 \%$. $^{22}$

Percobaan mengenai efektivitas minyak atsiri terhadap Microsporum canis telah dilakukan beberapa peneliti seperti Chuang et al menyatakan bahwa Moringa oleifera Lam memiliki kadar hambat minimal $0,4 \mu \mathrm{g} / \mathrm{ml}$ (400 ppm) terhadap M. canis. ${ }^{23}$ Penelitian serupa juga dilakukan Jantan et al dan Tao et al terhadap spesies Cinnamomum (C. pubescens, C. impressicostatum, C. microphyllum, C. scortechinii, C. rhyncophyllum, C. cordatum, C. zeylanicum, C. mollissimum dan C. longepaniculatum). Disimpulkan bahwa minyak atsiri tersebut memiliki efek antifungi yang baik. ${ }^{20,24}$ Minyak atsiri Coriandrum sativum pun menunjukkan aktifitas antijamur yang baik terhadap $M$. canis. $^{25}$ Thymus serpillum, Origanum vulgare dan Rosmarinus officinalis juga telah duji terhadap Microsporum canis secara in vitro dan in vivo oleh Mugnaini et.al menyebutkan bahwa secara in vitro $T$. serpillum dan Origanum vulgare menunjukkan MIC terendah, diiikuti $I$. verum, $R$. officinalis dan $C$. limon, untuk uji in vivo, digunakan $5 \%$ O. vulgare, $5 \% \quad R$. officinalis dan $2 \% \quad T$. serpillum, dalam sweet almond oil, empat dari tujuh perlakuan terhadap microsporiasis kucing dinyatakan sembuh, menunjukkan potensi minyak atsiri sebagai antifungi ${ }^{26}$

Pengujian aktivitas minyak atsiri sebagai komplementer pun dilaporkan oleh Zuzarte et al, kombinasi minyak atsiri Pelargonium graveolens (senyawa utama berupa sitronelal dan geraniol) dengan ketokonazol, melawan Tricophyton spp. Aktivitas antifungi ketokonazol secara signifikan ditingkatkan dengan senyawa alami dan dosis efektif minimal nya juga berkurang. Selanjutnya dijelaskan efek kombinasi beberapa minyak atsiri dan senyawa utamanya dengan flukonazol terhadap isolat klinis $T$. rubrum. Tingkat sinergisme maksimum ditemukan antara cinnamaldehyde dan flukonazol, senyawa ini mampu mengurangi MIC flukonazol hingga 8 kali lipat dan mengurangi MIC cinnamaldehyde hingga 32 kali lipat. Juga minyak esensial dari Syzigium aromaticum menunjukkan pengurangan tertinggi MIC (hingga 128 kali lipat) dalam kombinasi dengan flukonazol sehingga meminimalkan kemungkinan efek samping. ${ }^{10}$ 


\section{KESIMPULAN}

Minyak atsiri daun serai wangi, daun kayu manis dan daun sarasah cengkeh efektif dalam menekan pertumbuhan $M$. canis secara in vitro. Ketiga minyak atsiri pada konsentrasi 500 ppm telah mampu menghambat pertumbuhan M. canis hingga 100\%.

Minyak atsiri daun sarasah cengkeh memiliki efek antifungi paling tinggi (89,17\%), diikuti minyak atsiri daun serai wangi $(80,98 \%)$ dan kayu manis $(77,07 \%)$

\section{DAFTAR PUSTAKA}

1. Brajac I, Sosa LS, Prpic L, Loncarek K, Gruber F. The epidemiology of microsporum canis Infections in Rijeka Area, Croatia. Mycoses. 2004;47:222-26.

2. Asticcioli S, Silverio AD, Sacco L, Fusi I, Vicenti L, Romero E. Dermatophyte infections in patients attending a tertiary care hospital in Northern Italy. New Microbiologica. 2008;31:543-48.

3. Mulyati, Sjarifuddin PK, Susilo J. Mikosis superfisial. Dalam: Susanto I, Ismid IS, Sjarifuddin PK, Sungkar S, editor (penyunting). Buku Ajar Parasitologi Kedokteran. Edisi ke-4. Jakarta: Balai Penerbit Fakultas Kedokteran Universitas Indonesia; 2008. hlm.311-3.

4. Bramono K. Chronic recurrent dermatophytosis in the tropics: studies on tinea imbricata in Indonesia. Korean J Med Mycol.2012;17(1):1-7.

5. Falahati M, Akhlaghi L, Lari AR, Alaghehbandan R. Epidemiology of dermatophytoses in an Area South of Terhran, Iran. Mycopathologia. 2003;156: 279-87.

6. Basuki E, Suriadi, Bamono K. Pevalensi tinea kruris pada pekerja usaha makanan 'seafood kaki lima' dan berbagai faktor yang mempengaruhinya. Jakarta: Fakultas Kedokteran Universitas Indonesia; 2004.

7. Havlickova B, Czaika VA, Friedrich M. Epidemiological trends in skin mycoses worldwide. Mycoses. 2008;51(4):2-15.

8. Hidayati AN, Suyoso S, Hinda D, Sandra E. Mikosis superfisialis di divisi mikologi unit rawat jalan penyakit kulit dan kelamin RSUD Dr. Soetomo Surabaya tahun 2003-2005. Berkala IImu Kesehatan Kulit dan Kelamin. 2009;21(1):1-8.
9. Agustine R. Perbandingan sensitivitas dan spesifisitas pemeriksaan sediaan langsung $\mathrm{KOH}$ $20 \%$ dengan sentrifugasi dan tanpa sentrifugasi pada tinea kruris (tesis). Padang: Fakultas Kedokteran Universitas Andalas;2012.

10. Zuzarte M, Goncalves MJ, Canhoto J, Salgueiro L. Antidermatophytic activity of essential oils. Science against microbial pathogens. Communicating Current Research and Technological Advances. 2011;2:1167-78.

11. Nurmansyah. Pengaruh pemberian bahan tambahan dan jenis pelarut terhadap daya antifungal pestisida nabati minyak limbah kayu manis.Jurnal Dinamika Pertanian. 2006;21(2):11520.

12. Nassar MI, Gaara AH, Ghorab AHE, Farrag ARH, Shen $\mathrm{H}$, Huq $\mathrm{E}$, et al. Chemical constituents of clove (syzygium aromaticum, fam.myrtaceae) and their antioxidant activity. Rev. Latinoamer. Quím. 2007;35(3):47-57.

13. Park MJ, Gwak KS, Yang I, Choi WS, Jo HJ, Chang JW, et al. Antifungal activities of the essential oils in syzygium aromaticum (L.) merr. et perry and leptospermum Petersonii Bailey and their constituents against various dermatophytes. The Journal of Microbiology. 2007;45(5):460-5.

14. Martos MV, Navajas YR, Lopez JF, Alvarez JAP. Antifungal activities of thyme, clove and oregano essential oils. Journal of Food Safety. 2007;27:91101.

15. Chee HY, Lee MH. Antifungal activity of clove essential oil and its volatile vapour against dermatophytic fungi. Mycobiology. 2007; 35(4): 241-3.

16. Pinto E, Silva LV, Cavaleiro C, Salgueiro L. Antifungal activity of the clove essential oil from syzygium aromaticum on candida, aspergillus and dermatophyte species. Journal of Medical Microbiology. 2009;58:1454-62.

17. Nakahara K, Alzoreky NS, Yoshihashi T, Nguyen HT, Trakoontivakorn G. Chemical composition and antifungal activity of essential oil from cymbopogonnardus (citronella grass). JARQ Japan: Japan International Research Center for Agricultural Sciences. 2003;37(4):249-52. 
18. Billerbek VG, Roques CG, Bessiere JM, Fonvieille JL, Dargent L. Effects of cymbopogon nardus (L.) W. Watson essential oil on the growth and morphogenesis of aspergillus niger. Can. J. Microbiol. 2001;47:9-17.

19. Dhubiab BEA. Pharmaceutical applications and phytochemical profile of cinnamomum burmannii. Pharmacogn Rev. 2012;6(12):125-31.

20. Jantan I, Moharam BAK, Santhanam J,Jamal JA. Correlation between chemical composition and antifungal activity of the essential oils of eight cinnamomum species. Pharmaceutical Biology. 2008;46(6):406-12.

21. Muis R, Aziz A, Anwar A, Ferry $Y$, Usman M, Sudjarmoko, et al, editor (penyunting). Pedoman teknis budidaya kayu manis. Jakarta: Departemen Pertanian Direktorat Jendral Perkebunan. 2008; $1-$ 15.

22. Nurmansyah. Uji efikasi minyak kayu manis (cinnamomum burmanii) terhadap jamur fusarium oxysporum. Dalam: Prosiding Kongres XVI dan Seminar Perhimpunan Fitopatologi Indonesia.
Bogor: Perhimpunan Fitopatologi Indonesia. 2002; 260-4.

23. Chuang PH, Lee CW, Chou JY, Murugan M, Shieh BJ, Chen HM. Anti-fungal activity of crude extracts and essential oil of moringa oleifera lam. Bioresource Technology. 2007;98:232-6.

24. Tao C, Wei Q, Yin ZQ, Zhou LJ, Jia RY, Xu J, et al. Antifungal activity of essential oil from cinnamomum longepaniculatum leaves against three dermatophytes in vitro. African Journal of Pharmacu and Pharmacology. 2013;7(19):114852.

25. Soares BV, Morais SM, Fontenelle RODS, Queiroz VA, Nova NSV, Pereira CMC, et al. Antifungal activity, toxicity and chemical composition of the essential oil of coriandrum sativum L. fruits. Molecules. 2012;17:8439-48.

26. Mugnaini L, Nardoni S, Pinto L, Pistelli L, Leonardi $\mathrm{M}$, Pisseri $\mathrm{F}$, et al. In vitro and In vivo antifungal activity of some essential oils againts feline isolate of microsporum canis. Journal Mycologie Medicale. 2012;22(2):179-84. 